\title{
Ubiquitous burden: the contribution of migration to AIDS and Tuberculosis mortality in rural South Africa
}

\author{
Bocquier, Philipe ${ }^{1,2}$, Collinson, Mark A. 2,3,4, Clark, Samuel J.2,4,5,6, Gerritsen, Annette \\ A.M. ${ }^{2,4}$, Kahn, Kathleen ${ }^{2,3,4}$ and TollMan, Stephen M. ${ }^{2,3,4}$ \\ ${ }^{1}$ Université Catholique de Louvain, Louvain-la-Neuve, Belgium \\ ${ }^{2}$ MRC/Wits Rural Public Health and Health Transitions Research Unit (Agincourt), School of Public \\ Health, Faculty of Health Sciences, University of the Witwatersrand, Johannesburg, South Africa \\ ${ }^{3}$ Centre for Global Health Research, Umeå University, Sweden \\ ${ }^{4}$ INDEPTH Network, Accra, Ghana \\ ${ }^{5}$ University of Washington, Seattle, USA \\ ${ }^{6}$ Institute of Behavioral Science (IBS), University of Colorado at Boulder
}

\begin{abstract}
The paper aims to estimate the extent to which migrants are contributing to AIDS or tuberculosis (TB) mortality among rural sub-district populations. The Agincourt (South Africa) health and socio-demographic surveillance system provided comprehensive data on vital and migration events between 1994 and 2006. AIDS and TB cause-deleted life expectancy, and crude death rates by gender, migration status and period were computed. The annualised crude death rate almost tripled from $5 \cdot 39$ [95\% Cl 5.13-5.65] to $15 \cdot 10$ [95\% Cl 14.62-15.59] per 1000 over the years 1994-2006. The contribution of AIDS and TB in returned migrants to the increase in crude death rate was $78 \cdot 7 \%$ [95\% Cl $77 \cdot 4-80 \cdot 1]$ for males and $44 \cdot 4 \%$ [95\% Cl 43.2-46.1] for females. So, in a typical South African setting dependent on labour migration for rural livelihoods, the contribution of returned migrants, many infected with AIDS and TB, to the burden of disease is high.
\end{abstract}

Keywords: Migration; Mortality; AIDS; Tuberculosis; HDSS

\section{Résumé}

L'objectif de cet article est d'estimer dans quelle mesure les migrants contribuent à la mortalité due au Sida et la tuberculose (TB) dans les localités rurales. Les données sur les événements vitaux et migratoires proviennent de l'observatoire sociodémographique et de santé d'Agincourt (Afrique du Sud) pour la période 1994-2006. L'espérance de vie en l'absence de Sida/TB, ainsi que les taux bruts de mortalité ont été calculés par sexe, statut migratoire et période. Le taux brut de mortalité a presque triplé de 5.39 [IC $95 \% 5 \cdot 13-$ 5.65] à 15.10 [IC 95\% 14.62-15.59] pour 1000 sur la période 1994-2006. La contribution des migrants de retour atteints du Sida/TB à l'augmentation de ce taux brut de mortalité est de 78.7\% [IC 95\% 77.4-80.I] pour les hommes et de 44.4\% [IC 95\% 43.2-46.I] pour les femmes. Ainsi, dans un milieu rural sud-africain typique dépendant de la migration de main-d'œuvre pour sa survie, les migrants de retour, dont bon nombre sont atteints du Sida/ TB, contribuent grandement au fardeau des maladies.

Mots-clés: Migration; Mortalité; Sida; Tuberculose; Observatoires de population

\section{Introduction}

In 2010 UNAIDS/WHO reported that some $11.2 \%$ of the South African population was living with HIV (some 5.6 million people infected) (UNAIDS, 20I0). Following pervasive government denial and weak implementation of programmes, renewed political commitment made that currently voluntary counselling and testing and highly active antiretroviral therapy (HAART) are scaled-up, as well as access to condoms and expand tuberculosis (TB) control efforts (Abdool Karim et al., 2009). After the decision in 2003 to provide free public access to HAART coverage increased from $4.9 \%$ of those requiring it to $40.2 \%$ in 2008 (Adam and Johnson, 2009). However, improvements were not felt equally; poorer rural provinces such as Limpopo and the 
Eastern Cape (Hoogeveen and özler, 2006) experienced the lowest levels of HAART coverage ( 32.2 and $32.4 \%$ of those eligible) (Adam and Johnson, 2009). Constraints to HAART delivery included weak services coupled with poor management and out-migration of skilled health staff (Kober and Van Damme, 2004). Other factors included poor drug distribution and service delivery.

The goal of the government's HIV/AIDS and Sexually Transmitted Infections Strategic Plan for 2007-20 II was to initiate HAART in $80 \%$ of the population in need (Adbool Karim et al., 2009). It remains to be seen whether existing rural-urban inequities affect the distribution of these services as well as the return of labour migrants who are (terminally) ill to their rural areas of origin.

The paper aims to estimate the extent to which migrants are contributing to AIDS or TB mortality among rural sub-district populations.

\section{Literature Review}

Migration and health hold a complex relationship (Norman et al., 2005; Gushulak and MacPherson, 2006). The direction and impact of the relationship depend on the type of migration, the health measure and the setting. Migration between settings with different disease burdens can change the health profiles of migrants, host communities and origin communities (Gushulak and MacPherson, 2006). If healthier people migrate, over time this will lower the overall health status at origin, whereas at the destination health effects largely reflect local disease burden. There can be escalating risks for migrants in the destination population, for example of acquiring a sexually transmitted infection or occupational disease, or risks could reduce over time through migrants acquiring better knowledge of the host community and access to its health systems. Migrants are not a random sample of the origin population, but tend to have more skill, higher aspirations and better health status (Mbulaiteye et al., 2002; Lu, 20l0). This is particularly the case when the origin is more deprived than the destination, as often holds with rural to urban migration. An example is the migration of skilled health professionals leaving poorer communities for urban environments, thus lowering the quality of care available in already deprived settings (Kober and Van Damme, 2004). However, counter effects are possible when people with poorer health migrate from a better resourced (often urban) situation to a poorer one, seeking the benefit of family care despite a decline in access to health services (Norman et al., 2005; Clark et al., 2007).

In South Africa, rural livelihoods were severely disrupted by apartheid and in 1986 legislation that restricted migration was lifted (Reed, 20I3). The level of urbanisation in South Africa rose to $56 \%$ in the $200 \mathrm{I}$ national census (Kok and Collinson, 2006) and $62 \%$ in $201 \mathrm{II}$ (United Nations, 20I I), but circular migration increased considerably over this period, especially for women and younger men (Collinson, 20I0).

Poor urban conditions, rural attachment and cheaper transport have led to a rapid rise in circular migration (Collinson et al., 2007). This pattern involves a household deliberately sending a migrant, often a person endowed with health and skills, to an urban environment as part of a strategy to improve household welfare, distribute economic risks and diversify livelihoods (Taylor, 1999). When these migrants fall ill they are likely to return to their origin communities. This movement is hidden to policymakers because it counters the 'healthy migrant hypothesis' (Hu et al., 2008; Lu, 2008) and is not easily detectable in censuses and national surveys.

South Africa has been a focus for studies on migration and HIV (Quinn, 1994; Decosas et al., 1995; Lurie et al., 1997; Williams and Campbell, 1996; Lurie, 2006; Coffee MP, 2007). An important advance in understanding the link between exposure to migration and HIV/AIDS was the shift in perspective from one where migration serves to distribute HIV, to the insight that certain types of migration favour HIV epidemics (Decosas et al., 1995). Migration relates to HIV transmission; however migration itself is a complex variable to define and measure. Selection occurs at an individual level because migrants are typically young and healthy (Garenne, 20I0); they may be at higher risk of sexually transmitted infections due to risky behaviour. Disruption of family life and normal sexual relations can produce a loosening in social controls (Brockerhoff and Biddlecom, 1999; Yang et al., 2007); urban work environments may be more conducive to casual sex and alcohol consumption (Yang et al., 2007; Brockerhoff and Biddlecom, 1999). There may be anxiety associated with familial disruption (Yang et al., 2007). A migrant partner away from home for an extended period can influence sexual networks for the remaining partner; a combination of sexual and financial needs influence the risk of extramarital relationships, which, if accompanied by unprotected sex, can lead to the spread of HIV (Lurie et al., 2003; Brockerhoff and Biddlecom, 1999).

\section{Data and Methods}

\section{The study population}

The study is located in the Agincourt sub-district of Bushbuckridge, a typical former 'Bantustan' in the Mpumalanga Province of South Africa, $500 \mathrm{~km}$ northeast of Johannesburg. The study population 
comprised an average of 55000 residents (living in 12000 households) with an additional 20000 linked migrants living elsewhere. In the resident population, the sex ratio was 0.8 (reflecting high male labour migration). The crude death rates increased from 5.5 per 1000 to 15.8 per 1000 while the life expectancy decreased from 68 to 46 during the study period (1994-2006). The fertility transition in the subdistrict is almost complete with total fertility rate falling from 6.0 per woman in 1979 to 2.3 per woman in 2004 (Garenne et al., 2007). Unemployment rates are high at some $29 \%$ for men and $46 \%$ for women (Collinson, 20I0). Formal employment involves migrant men in the mining sector, construction, security and agricultural work. Women are a growing proportion of labour migrants working domestically and on fruit or game farms. Local employment is mostly in the public sector. Informal activities include the sale of fruit, cooked food and cheap snacks. State pensions are an important source of income. Almost a third of households are female-headed (32\%). Despite significant infrastructure investment, water shortages remain and household sanitation, largely pit latrines, are poor. Public transport is limited to privately owned mini-bus taxis and buses. Electricity and mobile phone services have expanded in recent years (Kahn et al., 20I2).

The sub-district primary health care system involves a network of two health centres and six clinics staffed by nurses. Since 1994, services have been free at point of delivery and include child health, family planning, antenatal, delivery and post-partum care, minor ailments and chronic disease treatment. Referrals are to three district hospitals between 25 and 60 kilometres away. Since 2005, HAART has been available at these hospitals. The communitybased initiation of HAART began with a public-private partnership, the Bhubezi Community Health Centre, in 2007, and at the public health centre in 2009.

\section{Health and socio-demographic surveillance}

In Agincourt sub-district, the HDSS provides annual updates of births, deaths, and in- and outmigration events have occurred since a baseline census in 1992. Each year, a visit is made to every household by supervised fieldworkers who interview the best respondent available. The fieldworker verifies the existing register and updates all vital events since the preceding visit (Kahn K. et al., 2007). To improve data quality, household rosters are preprinted and a $2 \%$ sample of duplicate household visits made.

The definition of migrant was whether a person was resident in the sub-district for more than six months in the preceding year (Kahn et al., 20I2). The number of migration events was divided by personyears experienced by the population to produce migration rates which can be stratified by sex, age and period of migration. Although migration is sensitive to recall bias, the annual update and a series of quality checks reduce this limitation. In addition, individual movements within the field site are 'reconciled' systematically so that the database can keep track of individuals when they move.

A verbal autopsy (VA) was conducted on every death to establish the probable main, immediate and contributing causes (Tollman et al., 2008; Kahn K. et al., 2007; Kahn et al., 20I2). The interview was conducted in Xi Tsonga by a trained lay fieldworker who collected information from a close caregiver on signs and symptoms of the terminal illness including lifestyle risk behaviours and treatment. Questionnaires were assessed independently by medical practitioners who coded diagnoses according to the International Classification of Diseases (ICD10). Where two physicians concurred on a diagnosis, this was accepted as the probable cause of death. Where their assessments differed, the VA was reviewed by a third physician in an effort to reach consensus; where this was not possible, the cause of death was assigned to and 'undetermined' category.

Performance of the verbal autopsy instrument was validated in the Agincourt sub-district by comparing VA findings with hospital recorded causes of death (Kahn et al., 2000; Fottrell E et al., 20I0). Since 1998, emphasis was placed on detecting deaths from AIDS. Misclassification with co-morbid conditions, particularly TB, reduced the sensitivity for both conditions since, in southern Africa, the great majority of patients with active TB are also infected with HIV. Hence, HIV/AIDS and TB were combined resulting in sensitivity and specificity approaching $80 \%$ for the single category. A similar approach has been adopted elsewhere (Hosegood et al., 2004; Setel et al., 2006). In determining cause of death from the verbal autopsy interview the symptoms may not be specific enough to establish a definitive cause. In the period 2002 to $2005,21 \%$ of all-cause mortality was undetermined (Tollman et al., 2008).

\section{Methods}

A competing risks framework was applied to obtain cause-deleted life-tables. Such life-tables provide the life expectancy and crude death rates at all ages for male and females. Classic cause-deleted life-tables assume independence of risks over time which implies that the age pattern of death at a particular time does not influence the pattern at a subsequent time. In contrast, the competing risks framework developed by Fine and Gray employs the 
cumulative incidence function to produce causedeleted life tables without assuming that the competing risks are independent from each other (1999). For an excellent introduction to the method, see Kim (Kim, 2007). To estimate the proportion of excess mortality attributable to returned migrants with AIDS and/or TB, the life table for the population was computed with and without returned migrants and, similarly, with and without deaths from AIDS and/or TB. Survival probabilities were computed using I-month intervals for the first year of life and single-year intervals thereafter; an $85+$ open-age interval was introduced because I-year estimates beyond 85-years are not reliable given small numbers.

\section{Results}

A summary of vital event and migration rates for the period 1994-2006 is shown in Table I. All figures are per 100 and not per 1000 so that the mortality, fertility and migration components of the basic demographic equation are readily interpretable in term of population growth, usually expressed in percentage. To note, mortality and in-migration have negative effects on population growth, hence negative figures. Despite non-linear trends, the general pattern was of intensifying migration with levels of in-, out- and gross migration showing marked increase. The mortality pattern showed a crude death rate almost tripling over the 12-year period; the crude birth rate remained almost constant and the rate of natural increase halved. Overall, the size of the permanently resident population decreased due to constantly increasing mortality and a peak of net out-migration during the 1998-2002 period.

Table I: Vital event and migration rates in rural South Africa (Agincourt sub-district), 1994-2006

\begin{tabular}{|c|c|c|c|c|}
\hline & Annual Rate & I 994 to 1997 & 1998 to 2002 & $\begin{array}{c}2003 \text { to mid- } \\
2006 \\
\end{array}$ \\
\hline \multirow[t]{9}{*}{ Males } & In-migration (I) & $7.97 \%$ & $10.36 \%$ & II. $.09 \%$ \\
\hline & Out-migration (2) & $-9.40 \%$ & $-16.55 \%$ & $-13.00 \%$ \\
\hline & Gross migration $|(I)|+|(2)|$ & $17.37 \%$ & $26.91 \%$ & $24.10 \%$ \\
\hline & Net migration $(I)+(2)$ & $-1.43 \%$ & $-6.19 \%$ & $-1.91 \%$ \\
\hline & Crude birth rate (3) & $2.77 \%$ & $2.85 \%$ & $3.06 \%$ \\
\hline & Crude death rate (4) & $-0.66 \%$ & $-1.09 \%$ & $-1.91 \%$ \\
\hline & Natural increase (3)-(4) & $2.11 \%$ & $1.75 \%$ & $1.15 \%$ \\
\hline & Total growth rate & $0.68 \%$ & $-4.44 \%$ & $-0.76 \%$ \\
\hline & Population size (yearly average) & 27117 & 24205 & 22301 \\
\hline \multirow[t]{9}{*}{ Females } & In-migration (I) & $7.65 \%$ & $10.53 \%$ & $10.91 \%$ \\
\hline & Out-migration (2) & $-9.17 \%$ & $-14.30 \%$ & $-12.09 \%$ \\
\hline & Gross migration $|(1)|+|(2)|$ & $16.81 \%$ & $24.83 \%$ & $23.00 \%$ \\
\hline & Net migration $(I)+(2)$ & $-1.52 \%$ & $-3.77 \%$ & $-1.17 \%$ \\
\hline & Crude birth rate (3) & $2.34 \%$ & $2.29 \%$ & $2.25 \%$ \\
\hline & Crude death rate (4) & $-0.45 \%$ & $-0.83 \%$ & $-1.32 \%$ \\
\hline & Natural increase (3)-(4) & $1.88 \%$ & $1.46 \%$ & $0.93 \%$ \\
\hline & Total growth rate & $0.36 \%$ & $-2.31 \%$ & $-0.25 \%$ \\
\hline & Population size (yearly average) & 32780 & 30791 & 29488 \\
\hline \multirow[t]{11}{*}{ Total } & In-migration (I) & $7.79 \%$ & $10.45 \%$ & $10.99 \%$ \\
\hline & Out-migration (2) & $-9.27 \%$ & $-15.30 \%$ & $-12.48 \%$ \\
\hline & Gross migration $|(I)|+|(2)|$ & $17.07 \%$ & $25.75 \%$ & $23.47 \%$ \\
\hline & Net migration $(I)+(2)$ & $-1.48 \%$ & $-4.84 \%$ & $-1.49 \%$ \\
\hline & Crude birth rate (3) & $2.54 \%$ & $2.53 \%$ & $2.60 \%$ \\
\hline & Crude death rate (4) & $-0.55 \%$ & $-0.95 \%$ & $-1.58 \%$ \\
\hline & Natural increase (3)-(4) & $1.99 \%$ & $1.58 \%$ & $1.02 \%$ \\
\hline & Total growth rate & $0.51 \%$ & $-3.26 \%$ & $-0.47 \%$ \\
\hline & Population size (yearly average) & 59897 & 54996 & 51789 \\
\hline & Male to female ratio & 0.827 & 0.786 & 0.756 \\
\hline & Age dependency ratio & 1.020 & 1.039 & 1.008 \\
\hline
\end{tabular}

Note: All variation in rates from one period to the next are significant, except for crude birth rates; 
Age dependency ratio $=$ ratio of the dependent population $(<15+\geq 65$ years) to those of working age (I5-64 years)

Mortality in general was higher for males and increased for both sexes, but the increase was more rapid for males. The life table provides life expectancies at birth (Table 2) which changed markedly from 1994-1997 to 2003-2006. Trends in life expectancy showed a decline of 22.5 years, only slightly less for females than for males. The effect of the decline on males was more pronounced as their life expectancy was already 14. I years lower in 19941997 than female life expectancy. The contribution of returned migrants to reduced life expectancy was $1 \cdot 6$ years in the first period 1994-1997 (0.2 years for females, 2.8 years for males); but 8.5 years in the latest period 2003-2006 (5.2 years for females, $10 \cdot 4$ years for males). Over the entire period, the contribution of returned migrants to the decline in life expectancy was 6.9 years [95\% Cl 6.5-7.2], which is $30 \cdot 6 \%$ [95\% Cl 29.6-31.6] of the total $22 \cdot 5$ years lost. Disaggregating by gender resulted in $23.4 \%$ [95\% Cl 22.2-24.2] of the decline in female life expectancy and $34 \cdot 6 \%$ [95\% Cl 32.6-36.3] in males contributed by returned migrants dying from AIDS or TB. Excluding deaths from AIDS and TB among recently returned migrants showed this component of mortality contributing $41 \cdot 3 \%$ to the overall loss in life expectancy, with a marked disparity by gender: $57 \cdot 6 \%$ [95\% Cl 57.0-58.4] for males and $31 \cdot 6 \%$ [95\% Cl 31·6-32.0] for females. 
Table 2: Life expectancy at birth (e0) by gender and period controlling for separate and combined effects of AIDS and TB, and recently returned migrants, Agincourt sub-district South Africa, 19942006.

\begin{tabular}{|c|c|c|c|c|c|}
\hline & & $\begin{array}{c}\text { e0 } 1994 \text { to } \\
1997[95 \% \mathrm{Cl}]\end{array}$ & $\begin{array}{c}\mathrm{e0} 2003 \text { to } \\
\text { mid-2006 [95\% } \\
\mathrm{Cl}]\end{array}$ & $\begin{array}{l}\text { Loss in e0 } \\
{[95 \% \mathrm{Cl}]}\end{array}$ & $\begin{array}{c}\text { Effect } \\
\text { contribution } \\
\text { to loss in e0 } \\
{[95 \% \mathrm{Cl}]}\end{array}$ \\
\hline \multirow[t]{14}{*}{ Males } & (a) Observed & 60.0 & 38.0 & 22.0 & \\
\hline & & {$[57.7-62.4]$} & {$[36.6-39.4]$} & {$[21.1-22.9]$} & \\
\hline & (b) Excluding recent migrants & 62.8 & 48.4 & 14.4 & \\
\hline & & {$[60.2-65.5]$} & {$[46.0-50.9]$} & {$[14.2-14.6]$} & $(b-a) / a=$ \\
\hline & $(b-a)=$ recent migrant effect & 2.8 & 10.4 & 7.6 & $34.6 \%$ \\
\hline & & {$[2.5-3.1]$} & {$[9.4-11.4]$} & [6.9-8.3] & [32.6-36.3] \\
\hline & (c) Excluding AIDS/TB & 66.4 & 61.1 & 5.2 & \\
\hline & & [64.6-68.1] & {$[60.2-62.0]$} & [4.4-6.1] & $(c-a) / a=$ \\
\hline & $(c-a)=$ effect of $A I D S / T B$ & 6.4 & 23.1 & 16.7 & $76.1 \%$ \\
\hline & & [6.9-5.7] & {$[23.6-22.6]$} & {$[16.7-16.9]$} & [73.6-79.0] \\
\hline & (d) Excl. AIDS/TB of recent migrants & 62.7 & 53.4 & 9.3 & \\
\hline & & {$[60.8-64.6]$} & {$[52.3-54.5]$} & {$[8.5-10.1]$} & $(d-a) / a=$ \\
\hline & $(d-a)=$ effect of AIDS/TB of recent migrants & 2.7 & 15.4 & 12.7 & $57.6 \%$ \\
\hline & & [2.3-3.0] & {$[15.1-15.6]$} & {$[12.0-13.4]$} & [57.0-58.4] \\
\hline \multirow[t]{14}{*}{ Females } & (a) Observed & 74.1 & 52.7 & 21.4 & \\
\hline & & [7I.8-76.3] & {$[50.7-54.6]$} & {$[21.1-21.7]$} & \\
\hline & (b) Excluding recent migrants & 74.3 & 57.9 & 16.4 & \\
\hline & & {$[71.9-76.6]$} & {$[55.5-60.2]$} & {$[16.4-16.4]$} & $(b-a) / a=$ \\
\hline & $(b-a)=$ recent migrants effect & 0.2 & 5.2 & 5.0 & $23.3 \%$ \\
\hline & & {$[0.1-0.3]$} & {$[4.8-5.6]$} & {$[4.7-5.2]$} & [22.2-24.2] \\
\hline & (c) Excluding AIDS/TB & 76.0 & 70.3 & 5.7 & \\
\hline & & {$[74.3-77.7]$} & {$[69 .|-7| .4]$} & {$[5.2-6.3]$} & $(c-a) / a=$ \\
\hline & $(c-a)=$ effect of AIDS/TB & 1.9 & 17.6 & 15.7 & $73.2 \%$ \\
\hline & & [2.4-1.3] & {$[18.4-16.7]$} & {$[16.0-15.4]$} & [7I.0-75.5] \\
\hline & (d) Excl. AIDS/TB of recent migrants & 74.2 & 59.5 & 14.6 & \\
\hline & & {$[72.2-76.0]$} & {$[57.9-61.1]$} & [14.3-14.9] & $(d-a) / a=$ \\
\hline & $(d-a)=$ effect of AIDS/TB of recent migrants & 0.1 & 6.9 & 6.8 & $31.6 \%$ \\
\hline & & {$[-0.3-0.4]$} & [6.5-7.2] & [6.8-6.8] & {$[31.6-32.0]$} \\
\hline \multirow[t]{14}{*}{ Total } & (a) Observed & 68.3 & 45.8 & 22.5 & \\
\hline & & [66.6-69.9] & [44.6-47.I] & [22.0-22.9] & \\
\hline & (b) Excluding recent migrants & 69.9 & 54.3 & 15.6 & \\
\hline & & {$[68.1-7 \mid .6]$} & {$[52.6-56.0]$} & {$[15.5-15.6]$} & $(b-a) / a=$ \\
\hline & $(b-a)=$ recent migrants effect & 1.6 & 8.5 & 6.9 & $30.6 \%$ \\
\hline & & {$[1.5-1.7]$} & {$[8.0-8.9]$} & {$[6.5-7.2]$} & {$[29.6-31.6]$} \\
\hline & (c) Excluding AIDS/TB & 72.0 & 65.9 & 6.1 & \\
\hline & & {$[70.8-73.2]$} & {$[65.1-66.6]$} & {$[5.6-6.6]$} & $(c-a) / a=$ \\
\hline & $(c-a)=$ effect of $A I D S / T B$ & 3.8 & 20.1 & 16.3 & $72.7 \%$ \\
\hline & & {$[3.3-4.2]$} & {$[19.6-20.6]$} & {$[16.3-16.4]$} & {$[71.7-73.8]$} \\
\hline & (d) Excl. AIDS/TB of recent migrants & 69.4 & 56.2 & 13.2 & \\
\hline & & {$[68.0-70.7]$} & {$[55.2-57.2]$} & {$[12.8-13.6]$} & $(d-a) / a=$ \\
\hline & $(d-a)=$ effect of AIDS/TB of recent migrants & 1.1 & 10.4 & 9.2 & $41.3 \%$ \\
\hline & & {$[0.8-1.3]$} & {$[10.1-10.6]$} & [9.2-9.3] & [40.4-42.2] \\
\hline
\end{tabular}

Notes: (I) Recently returned migrations (i.e. recent migrants) are in-migrants with more than 6 months and less than 3 years permanent residence in the Agincourt sub-district. (2) Effect contribution to loss in $\mathrm{e} 0$ is computed by dividing the years lost to the effect by the total years lost between the periods. For example, the total population lost 22.452 years in life expectancy. However, if AIDS and TB deaths of recent migrants are excluded the loss is only 13.199 years. The contribution of AIDS and TB deaths of recent migrants is therefore 9.252 years $(22.452-13.199=9.252)$ i.e. $41.21 \%$ of the loss in e0 over the period $(9.252 / 22.452=0.4121)$. Differences between actual computation using exact values and figures in table are due to rounding.

In numeric terms, applying the crude death rate of 1994-1997 to the Agincourt population of 2003-2006 averages to about 284 deaths a year instead of the
816 deaths registered in the HDSS. Of the 532 extra deaths, 34 I (i.e.64\%) were due to recent migrants returning each year to die of AIDS and TB. 
Table 3: Annualised crude death rates (CDR) per 1000 person-years by gender and period, controlling for separate and combined effects of AIDS, TB and recently returned migrants, Agincourt sub-district, South Africa 1994-2006.

1994 to $1997[95 \% \mathrm{Cl}] \quad 2003$ to mid-2006 Effect contribution to CDR $[95 \% \mathrm{Cl}]$ increase $[95 \% \mathrm{Cl}]$

\begin{tabular}{|c|c|c|c|}
\hline Males & $6.64[6.17-7.14]$ & $\begin{array}{c}19.11[18.16- \\
20.10]\end{array}$ & \\
\hline $\begin{array}{r}\text { Excluding recent } \\
\text { migrants }\end{array}$ & $6.11[5.62-6.63]$ & $\begin{array}{c}12.58[1 \mid .73- \\
\mid 3.48]\end{array}$ & $48.1 \%[47.1-49.1]$ \\
\hline $\begin{array}{r}\text { Excluding AIDS/TB } \\
\text { deaths }\end{array}$ & $4.26[3.88-4.67]$ & $5.18[4.69-5.70]$ & $92.7 \%$ [92.0-93.3] \\
\hline $\begin{array}{r}\text { Excluding AIDS/TB } \\
\text { deaths in recent } \\
\text { migrants }\end{array}$ & $5.24[4.82-5.70]$ & 7.21 [ 6.63- 7.83] & $84.2 \%$ [83.5-85.0] \\
\hline Females & $4.53[4.18-4.90]$ & $\begin{array}{c}\text { I3.22 [12.54- } \\
\text { 13.94] }\end{array}$ & \\
\hline $\begin{array}{r}\text { Excluding recent } \\
\text { migrants }\end{array}$ & $4.74[4.35-5.16]$ & $\begin{array}{l}\mathrm{II} .32[10.6 \mathrm{I}- \\
\mathrm{I} 2.07]\end{array}$ & $24.3 \%[23.5-25.1]$ \\
\hline Excluding AIDS/TB & $3.57[3.25-3.91]$ & $5.07[4.65-5.52]$ & $82.8 \%[82.1-83.3]$ \\
\hline $\begin{array}{r}\text { Excluding AIDS/TB } \\
\text { deaths in recent } \\
\text { migrants }\end{array}$ & $4.10[3.76-4.46]$ & $8.56[8.00-9.14]$ & $48.8 \%$ [48.2-49.3] \\
\hline Total & $5.48[5.19-5.78]$ & $\begin{array}{c}15.76[15.19- \\
16.35]\end{array}$ & \\
\hline $\begin{array}{r}\text { Excluding recent } \\
\text { migrants }\end{array}$ & $5.37[5.05-5.69]$ & $\begin{array}{c}\text { I I. } 87 \text { [ I I.32- } \\
\text { I2.44] }\end{array}$ & $36.7 \%[36.1-37.3]$ \\
\hline Excluding AIDS/TB & $3.97[3.72-4.22]$ & $5.37[5.04-5.72]$ & $86.3 \%$ [85.9-86.8] \\
\hline $\begin{array}{r}\text { Excluding AIDS/TB } \\
\text { deaths in recent } \\
\text { migrants }\end{array}$ & 4.7I [4.44-5.00] & $8.40[7.98-8.83]$ & $64.1 \%[63.7-64.6]$ \\
\hline
\end{tabular}

Notes: (I) Recent migrants are migrants with more than 6 months and less than 3 years permanent residence in the Agincourt subdistrict. (2) Contribution to increase in CDR is computed by dividing the CDR increase due to the effect by the total CDR increase between the periods (as in Table 2). For example, the total population CDR increased by 10.28 per 1000 person-years (I5.76$5.48=10.28)$. Excluding AIDS and TB deaths of recent migrants, the increase is only 3.69 per 1000 person-years $(8.40-4.71=3.69)$. The contribution of AIDS and TB mortality in recent migrants is therefore 6.59 per 1000 person-years $(10.28-3.69=6.59)$, i.e. 64 . $1 \%$ of CDR increase over the period $(6.59 / 10.28=0.64 I)$.

Figures $I$ and 2 show the burden of mortality for returned migrants, contrasted with levels of mortality among non-migrants in different periods. They indicate the importance of the time since in-migration on characterising the mortality risk. A year after inmigration was the period of highest mortality risk suggesting that many migrants return home with already advanced illness. Male migrants show a significant and markedly increasing risk of death. The migrant death rate among males one year after moving back to rural Agincourt increased seven-fold from $2.5 \%$ [95\% Cl I.8-3.4] in 1994-1997 to $18.0 \%$ [95\% Cl 15.9-20.4] in 2003-2006, well above the non-migrant level of $2 \cdot 2 \%$ [ $95 \% \mathrm{Cl}$ ।.9-2.4]. Female migrants showed a lower but significant increase in death rate over the same period, from $0.5 \%[95 \%$ $\mathrm{Cl} 0 \cdot 3-0 \cdot 9]$ to $4 \cdot 8 \%$ [95\% Cl $4 \cdot 0-5 \cdot 7]$ against $1.7 \%$ $\left[\begin{array}{lll}95 \% & \mathrm{Cl} & 1.6-1.9\end{array}\right]$ for non-migrants. 


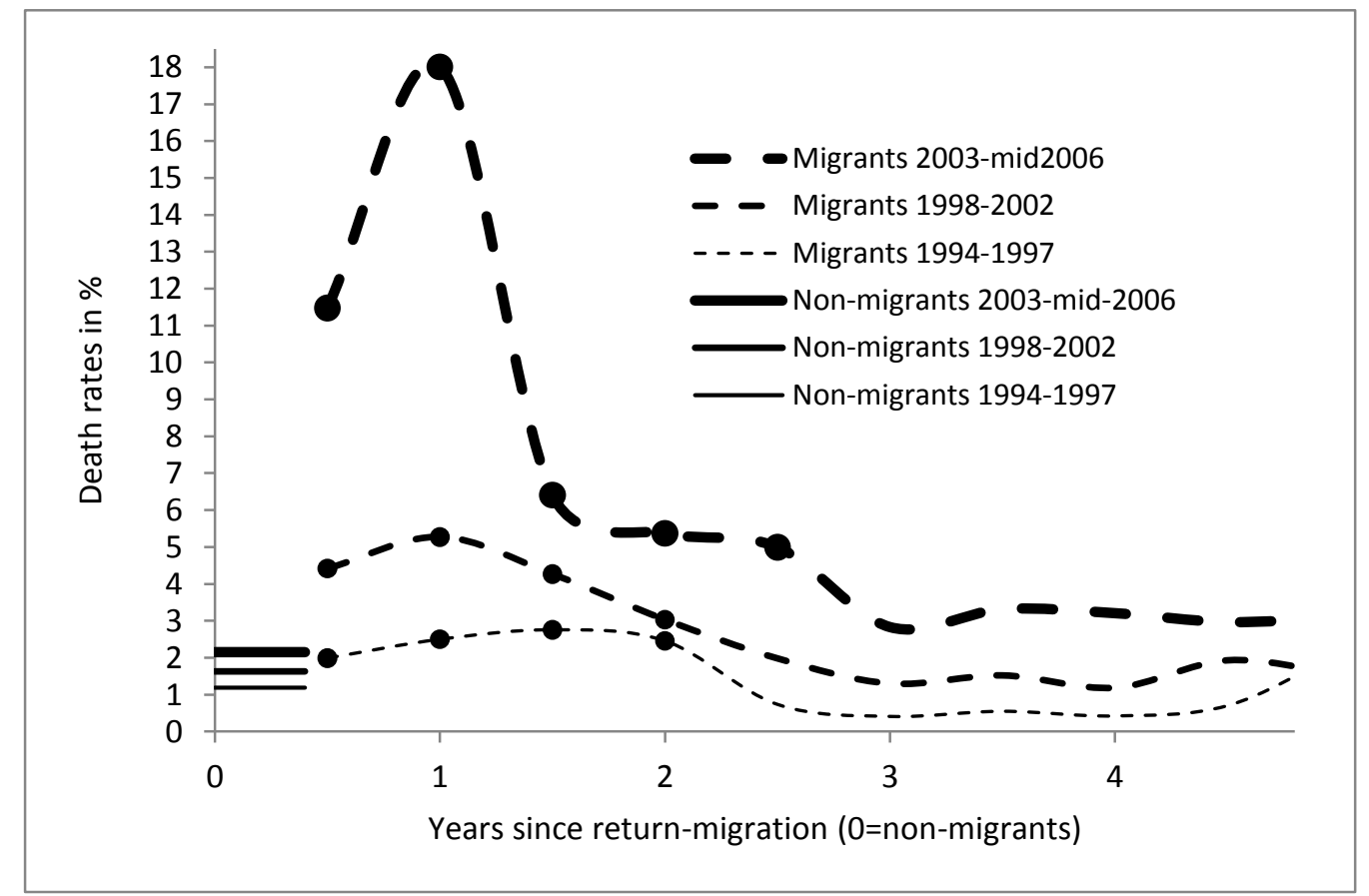

Figure I: Death rates of adult males $(18+)$ by duration of residence, Agincourt sub-district, South Africa (1994-2006).

Straight lines starting at year 0 refer to non-migrant males who never lived outside of the sub-district for more than 6 months a year for a period of 6 years or more. Broken lines denote in-migrant mortality with thicker lines showing more recent periods; and with dots showing where the death rate of migrants differed significantly $(p>0.05)$ from non-migrant for the same period.

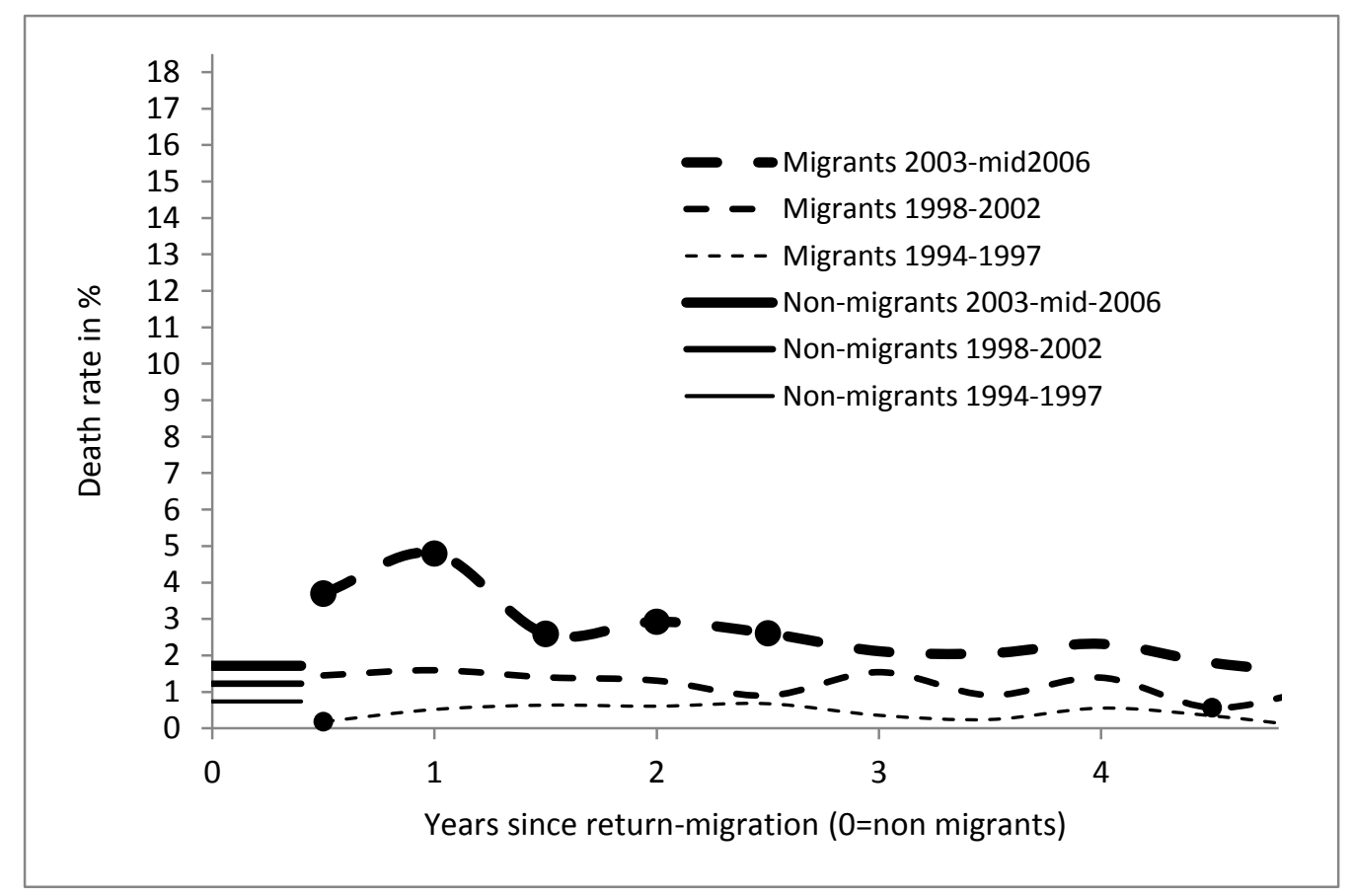

Figure 2: Death rates of adult females $(18+)$ by duration of residence, Agincourt sub-district, South Africa (1994-2006).

Straight lines starting at year 0 refer to non-migrant females who never lived outside of the sub-district for more than 6 months a year for a period of 6 years or more. Broken lines denote in-migrant mortality with thicker lines showing more recent periods; and with dots showing where the death rate of migrants differed significantly $(p>0.05)$ from non-migrant for the same period. 


\section{Discussion and Conclusion}

A barrier when examining migration-health relationships in low-income settings is incomplete vital registration and a paucity of data. A HDSS provides a whole population cohort, keeping track of household entry and exit as well as births and deaths by probable cause. South African rural areas are typical of labour sending communities in other countries in the southern African region. The Agincourt HDSS thus provides insight into the dynamics of birth, death, in and out-migration in poor rural communities in South and southern Africa with high levels of labour migration.

Findings show that the contribution of AIDS and TB deaths among returned migrants to the trend in rising crude death rate was much higher than their contribution to the loss in life expectancy due to the adjustment made for the age profile of mortality in the life expectancy measure. Furthermore, the contribution of recently returned migrants to the loss in life expectancy was more pronounced for males than females. Although female migrants contributed to this loss, male returning migrants appear more affected by AIDS and TB than non-migrant males and females. Female migration flows were only marginally less intense than those of males so the higher contribution male migrants to the loss in life expectancy cannot be attributed to a higher share in migration flows. Indeed, return migration rates show less gender difference than out-migration rates. Hence it is likely that differences in living conditions at migrants' destination, and their consequences for sexual behaviour and risk behaviour more generally contributed to the differential mortality impact of return migration by gender. Further investigation is needed to better understand how the phenomenon of "returning home to die" is associated with loss of household income through reduced remittances, increased cost of health care and funerals, and compounded by the value of household income foregone through another household member contributing care to a severely ill person (Clark et al., 2007).

From a health systems perspective, rising mortality in rural South Africa occurred in parallel with falling numbers of public sector beds. Strengthening health systems to support chronic care is vital due to the high prevalence of AIDS and TB as well as emerging non-communicable diseases in a context of rapid health transition (Tollman et al., 2008). A particular challenge arising from this ubiquitous impact of AIDS, TB and other chronic conditions is the need for effective clinic information systems and referral mechanisms capable of spanning long distances and covering rural, peri-urban and 699 urban areas to maintain continuity of care for labour migrants. Patient-retained health books (Kahn et al., 2006; Daniels et al., 2000) would assist primary health care systems to cater for a highly mobile population affected by AIDS and TB as well as chronic conditions such as diabetes and hypertension. Responses appropriate to rural South Africa are applicable across southern Africa given a regional economy heavily influenced by the South African mining, industrial and manufacturing sectors.

\section{Acknowledgements}

The Agincourt health and socio-demographic surveillance system is run by a committed team that includes F. Xavier Gómez-Olivé, Rhian Twine, Jeffrey Tibane, Ngoni Ngwarai, Paul Mee, Chodziwadziwa Kabudula and Sulaimon Afolabi. The communities of Bushbuckridge are valued and active partners. The Umeå Centre for Global Health Research is acknowledged, with support from FAS, the Swedish Council for Working Life and Social Research (Grant number: 2006-1512). Other funders: Wellcome Trust, UK (Grant numbers: 058893/Z/99/A; 069683/Z/02/Z; 085477/Z/08/Z); University of the Witwatersrand and Medical Research Council, South Africa; The William and Flora Hewlett Foundation (Grant 2008-1840), National Institute on Aging (NIA) of the NIH (Grants IR24AG032II2-0I and 5R24AG032II2-03), and The Andrew W Mellon Foundation, USA.

\section{Authors contributions}

$\mathrm{PB}$ and MAC conceptualised the paper, designed the study, prepared the data and conducted the analysis. PB wrote the sections on statistical analysis and results. MAC wrote the introduction, methods and discussion; SMT provided scientific leadership, introduced and led the health and socio-demographic surveillance system; KK was responsible for the verbal autopsies and their cause of death assessment; SC helped to develop the argument; MAC,SMT, KK oversaw data quality. AG coordinated the submission and the response to reviewers comments and finalised the paper. All authors reviewed and refined the manuscript.

The content of the manuscript has never been previously published.

\section{References}

Abdool Karim SS, Churchyard GJ, Abdool Karim Q, et al. 2009. HIV Infection and tuberculosis in South Africa: an urgent need to escalate the public health response. The Lancet 374: 921-933.

Adam MA and Johnson LF. 2009. Estimation of adult antiretroviral treatment coverage in South Africa. South African Medical Journal 99: 661-667. 
Adbool Karim SS, Churchyard GJ, Abdool Karim Q, et al. 2009. HIV Infection and tuberculosis in South Africa: an urgent need to escalate the public health response. The Lancet 374: 921-933.

Brockerhoff $M$ and Biddlecom AE. 1999. Migration, sexual behavior and the risk of HIV in Kenya. International Migration Review 33: 833-856.

Clark SJ, Collinson MA, Kahn K, et al. 2007. Returning Home to Die: Circular labour migration and mortality in rural South Africa. Scandinavian Journal of Public Health 35: 35-44.

Coffee MP LM, Garnette GP. 2007. Modeling the Impact of Migration on the HIV Epidemic in South Africa. AIDS 21: 343-350.

Collinson MA. 2010. Striving against adversity: The dynamics of migration, health and poverty in rural South Africa. Global Health Action. Global Health Action 3.

Collinson MA, Tollman SM and Kahn K. 2007. Migration, Settlement Change and Health in Post Apartheid South Africa: Triangulating Agincourt Demographic Surveillance with National Census Data. Scandinavian Journal of Public Health 35: 7784.

Daniels AR, Patel M, Biesma R, et al. 2000. A structured record to implement the national guidelines for diabetes and hypertension care. South African Medical Journal 90: 53-56.

Decosas J, Kane F, Anafi JK, et al. 1995. Migration and AIDS. Lancet 346: 826-828.

Fine JP and Gray RJ. 1999. A Proportional Hazard Model for the Subdistribution of a Competing Risk. Journal of the American Statistical Association 94: 496:509.

Fottrell E, Kahn K, Ng N, et al. 2010. Mortality measurement in transition: proof of principle for standardized multi-country comparisons. Tropical Medicine and International Health I5: I256- 265.

Garenne M. 2010. Urbanisation and child health in resource poor settings with special reference to under-five mortality in Africa. Archives of Disease in Childhood doi: 10.1 I36/adc.2009.172585.

Garenne M, Tollman SM, Kahn K, et al. 2007. Fertility trends and net reproduction in Agincourt, rural South Africa: 1992-2004. Scandinavian Journal of Public Health 35 68-76.

Gushulak BD and MacPherson DW. 2006. The basic principles of migration health: population mobility and gaps in disease prevalence. Emerging Themes in Epidemiology 3.

Hoogeveen J and özler B. 2006. Poverty and Inequality in Post-apartheid South Africa: 19952000. In: Bhorat $\mathrm{H}$ and Kanbur R (eds) Poverty and Policy in Postapartheid South Africa. Pretoria: HSRC Press.
Hosegood V, Vanneste A and Timaeus IM. 2004. Levels and causes of adult mortality in rural South Africa: The impact of AIDS. AIDS. AIDS 18: 663671.

Hu X, Cook S and Salazar MA. 2008. Internal migration and health in China. Lancet Vol 372 1717-1719.

Kahn K, Collinson MA, Gómez-Olivé FX, et al. 2012. Profile: Agincourt Health and socio-Demographic Surveillance System (Agincourt HDSS). International Journal of Epidemiology 4I:: 988-I00 I.

Kahn K, Tollman SM, Garenne M, et al. 2000. Validation and application of verbal autopsies in a rural area of South Africa. Tropical Medicine and International Health 5: 824-83I.

Kahn K, Tollman SM, Thorogood M, et al. 2006. Older Adults and the Health Transition in Agincourt, Rural Southern Africa: New understanding, Growing Complexity. . In: Menken $\mathrm{J}$ and Cohen B (eds) Aging in Sub-Saharan Africa: Recommendations for Furthering Research. Washington, D.C., USA.: National Academies Press, pp. 166-188.

Kahn K., Tollman SM, Collinson MA, et al. 2007. Research into health, population and social transitions in rural South Africa: Data and methods of the Agincourt Health and Demographic Surveillance System. . Scandinavian Journal of Public Health 35 8-20.

Kim HT. 2007. Cumulative Incidence in Competing Risks Data and Competing Risks Regression Analysis. Clinical Cancer Research I3: 559-565.

Kober K and Van Damme W. 2004. Scaling up access to antiretroviral treatment in southern Africa: who will do the job? The Lancet 364: 103-107.

Kok $P$ and Collinson MA. 2006. Migration and Urbanisation in South Africa. Report 03-04-02, Pretoria: Statistics South Africa.

Lu Y. 2008. Test of the 'healthy migrant hypothesis': A longitudinal analysis of health selectivity of internal migration in Indonesia. Social Science \& Medicine 67: |33|-|339.

Lu Y. 2010. Rural-urban migration and health: evidence from longitudinal data in Indonesia. Social Science \& Medicine 70: 4I2-4I9.

Lurie M. 2006. The Epidemiology of Migration HIV/AIDS in South Africa. Journal of Ethnic and Migration Studies 32: 649-666.

Lurie M, Wilkinson D, Harrison A, et al. 1997. Migrancy and HIV/STDs in South Africa - a rural perspective. South African Journal of Medicine 87: 908-909.

Lurie M, Williams B, Zuma K, et al. 2003. Who infect whom? HIV-I concordance and discordance among migrant and non-migrant couples in South Africa. AIDS I7: 2245-2252. 
Mbulaiteye SM, Mahe C, Whitworth JAG, et al. 2002. Declining HIV-I incidence and associated prevalence over 10 years in a rural population in south-west Uganda: a cohort study. The Lancet 360: 4 I-46.

Norman P, Boyle P and Rees P. 2005. Selective migration, health and deprivation: a longitudinal analysis. Social Science \& Medicine 60: 2755-277I.

Quinn TC. 1994. Population migration and the spread of types I and 2 human immunodeficiency viruses. Proceedings of the National Academy of Science, USA 91: 2407-24I4.

Reed H. 20I3. Moving across boundaries: migration in South Africa, 1950-2000. Demography 50: 7195.

Setel P, Whiting D, Hemed Y, et al. 2006. Validity of verbal autopsy procedures for determining cause of death in Tanzania. . Tropical Medicine and International Health. II 68I-690
Taylor J. 1999. The New Economics of Labour Migration and the role of remittances in the migration process. International Mlgration 37: 6386.

Tollman SM, Kahn K, Sartorius B, et al. 2008. Implications of mortality transition for primary health care in rural South Africa: a populationbased surveillance study. The Lancet 372: 893-901.

UNAIDS. 2010. Global report: UNAIDS Report on the Gobal AIDS epidemic. Geneva.

United Nations. 20I I. World Urbanization Prospects: The 2011 revision., New York: United Nations: Department of Economic and Social Affairs, Population Division.

Williams B and Campbell C. 1996. Mines, Migrancy and HIV in South Africa: managing the epidemic. South African Medical Journal 86: I249-I25I.

Yang X, Derlega VJ and Luo H. 2007. Migration, behaviour change and HIV/STD risks in China. AIDS Care 19: 282-288. 